\title{
RESPONSE TO PURIFIED CRY IB PROTEIN IN LAB-WILD TYPE CROSSES OF LIGHTBROWN APPLE MOTH
}

\author{
D.M. SUCKLING ${ }^{1}$, N.P. MARKWICK ${ }^{2}$, P.J. WIGLEY ${ }^{3}$, C. FRATER ${ }^{2}$, \\ C.N. CHILCOTT ${ }^{3}$ and J. MAINDONALD ${ }^{2}$ \\ ${ }^{1}$ HortResearch PO Box 51, Lincoln \\ ${ }^{2}$ HortResearch, PO Box 92169, Auckland \\ ${ }^{3}$ BioDiscovery NZ. Ltd., Titirangi
}

\begin{abstract}
A survey for genetic variability in response of Epiphyas postvittana to a purified Bacillus thuringiensis $\delta$-endotoxin (Cry IB) was conducted in order to assess the risk of development of resistance, prior to the deployment of transgenic apple trees. Tethered laboratory colony female moths were mated to feral males at sites in the North Island in 1993 and 1994. The progeny of iso-female lines were tested for response to two concentrations, or to a range of concentrations of purified toxin. The $\mathrm{LC}_{50} \mathrm{~s}$ varied by a factor of 4.3 fold in six iso-female lines from the 1993 collection. The lines were significantly more susceptible to Cry IB toxin than 14 iso-female lines originating from the second collection ( 7.2 fold range in $\mathrm{LC}_{50}$ ). The range in $\mathrm{LC}_{50} \mathrm{~S}$ of 20 field populations was 14 fold. This level of variation is similar to that reported for other species.
\end{abstract}

Keywords: Resistance, Bacillus thuringiensis, leafroller, apple, transgenic

\section{INTRODUCTION}

Current strategies to control insects in horticulture are increasingly recognised as imposing unacceptable costs to both the environment and human health, and could adversely impact on sectors outside horticulture (Christie 1993). Transgenic plants potentially offer very significant benefits for the production of high quality fruit with environmentally safe, sustainable and effective pest control (Wearing and Hokkanen 1994). Transgenic pest resistant plants therefore may be important components of future integrated pest management systems for many crops, including apples. Deployment of transgenic crops containing Bacillus thuringiensis (Bt) genes or other environmentally benign insecticidal proteins will undoubtedly have ecological consequences, including selection pressure for pest adaptation (Wearing and Hokannen 1994; Wigley et al. 1994). Several major pest species have already developed resistance to Bt-endotoxins in the laboratory, and some have evolved widespread resistance to Bt biopesticides in the field, making studies of Bt-susceptibility essential to assessing the risk of resistance (Tabashnik 1994). Resistance to transgenic plants expressing Bt toxins will probably occur (McGaughey and Whalon 1992). The appropriate time to measure baseline susceptibility of target pest species is obviously before deployment of such crops.

Leafrollers, which are the major quarantine pests of New Zealand apples, have developed resistance to chemical insecticides. For example, lightbrown apple moth (Epiphyas postvittana) has developed resistance to three classes of insecticides, probably by independent mechanisms (Suckling 1996). Resistance to organophosphates is also known in one native leafroller, Planotortrix octo (Wearing 1995). These pests have the potential to become resistant to Bt toxins, if inappropriate management of the Bt resource is used (Wigley et al. 1994). 
Management of the risk of resistance to transgenic crops may be possible through the design of suitable deployment strategies. One component necessary for the design of resistance management strategies, is information on the inherent population variability. Here we report the results of a survey for variability in response to Cry IB toxin in the North Island population of E. postvittana. This species was chosen because of its high polyphagy and previous resistance episodes (Suckling 1996). As part of the survey technique, we chose to cross susceptible laboratory female moths with feral male moths, an approach which has been used successfully to investigate the detoxication enzyme profile (Suckling et al. 1990) and frequency of insecticide resistance in the field (Suckling and Khoo 1993). This method facilitates ready collection of a large number of lines from single females (iso-female lines), as well as improving colony establishment on artificial diet (since one parent is laboratory adapted).

\section{Insect Collections}

\section{MATERIALS AND METHODS}

Two collections of $E$. postvittana were made during 1993-94, by mating tethered female moths from a laboratory colony with feral males in the field (Sucking and Khoo 1993) at sites throughout New Zealand. Detailed descriptions of the locations used are given in Wigley et al. (in prep.). Collection 1 (February-March 1993) consisted of progeny of mated females from sites in the Northern and Central North Island (plus one South Island site, Lincoln). Collection 2 (February-March 1994), was performed at sites in the Central North Island only. Larvae from the first collection were reared as isofemale lines on a wheatgerm-based diet (Singh 1983) for four generations. Neonate larvae of the fifth generation were used for bioassays. Eggs from Collection 2, were held at $10^{\circ} \mathrm{C}$ for 2 weeks before incubation at $22^{\circ} \mathrm{C}$. Neonate larvae, hatching from these eggs, were used for the bioassays. All dosage-mortality tests on larvae from both collections were conducted at the same time (March 1994). Field collections were compared with progeny of three (for $\mathrm{LC}_{50}$ ) or four laboratory crosses (for two dose tests).

\section{Toxin Preparation}

B. thuringiensis subsp. thuringiensis 4412 (crystal contains only CryIB, obtained from Plant Genetic Systems, Belgium) was grown on nutrient agar plates at $28^{\circ} \mathrm{C}$ until sporulation. The spore/crystal mixture was scraped from plates and washed three times with distilled water, twice with $1 \mathrm{M} \mathrm{NaCl}$, and a further three times with distilled water.

Crystal protein was solubilised in $50 \mathrm{mM} \mathrm{Na} \mathrm{CO}_{3}-10 \mathrm{mM}$ dithiothreitol, $\mathrm{pH} 9.5$ at $37^{\circ} \mathrm{C}$ for $60 \mathrm{~min}$. Insoluble material was removed by centrifugation. Trypsin was added to the supernatant to a final concentration of $100 \mathrm{mg} / \mathrm{ml}$, and incubated at $37^{\circ} \mathrm{C}$ for $16 \mathrm{~h}$. Trypsin activated protein was dialysed against several changes of phosphate-buffered saline (PBS), $\mathrm{pH} 8.5$, and stored in $4 \mathrm{ml}$ aliquots at $-90^{\circ} \mathrm{C}$ until required. Protein concentration was determined using a Bio-Rad protein assay kit with bovine gamma globulin as a standard (Bradford 1976). The thawed toxin was sonicated briefly before inclusion in the diet.

\section{Diet}

A wheatgerm diet was used in all trials. The following ingredients were mixed and autoclaved for 20 minutes: water $(1000 \mathrm{ml})$; wheatgerm $(30 \mathrm{~g})$; casein $(30 \mathrm{~g})$; sucrose (30 g); pasteurised yeast powder ( $20 \mathrm{~g})$; methyl-p-hydroxy benzoate $(1.5 \mathrm{~g})$; sorbic acid $(500 \mathrm{mg})$ and agar $(25 \mathrm{~g})$. The mixture was then cooled to $65^{\circ} \mathrm{C}$ and ascorbic acid $(3 \mathrm{~g})$, penicillin and streptomycin $(0.35 \mathrm{~g}$ each $)$ and prochloraz powder $(40 \mathrm{mg})$ were added.

Doses of toxin were added to the diet at $10 \%$ by volume (except for controls) and blended for 30 seconds before being dispensed into the wells of ELISA plates (approximately $100 \mu \mathrm{l} /$ well) using a syringe. The diets were allowed to condition for 2 hours before being inoculated with E. postvittana larvae (one/well). Each tray was then sealed with Mylar and Frisk film.

\section{Dosage-mortality Tests}

For each collection site, 16 neonate larvae were inoculated onto diet with each dose, replicated three times. Larvae were held at $25^{\circ} \mathrm{C}$, and mortality was recorded two weeks after inoculation. The six doses used ranged from 64 to $0.1 \mu \mathrm{g} / \mathrm{ml}$ diet (based on pilot studies), as well as a control. 


\section{Two Dose Tests}

The methods of preparation of diets and toxin used above for dosage-mortality tests were identical to those used for these tests except that only two concentrations of toxin $(83$ and $1.7 \mu \mathrm{g} / \mathrm{ml}$ diet $)$ plus a distilled water control were tested. The larvae tested were the offspring of individual females, which came from widely dispersed sites, lacking sufficient offspring for testing a wider range of concentrations. Twelve larvae per replicate were inoculated onto the test diets, replicated three times.

Analyses

Results of dosage-mortality tests were analysed assuming logit responses, after taking account of control mortality, using S-plus (Chambers and Hastie 1993) to estimate $\mathrm{LC}_{50}$ values and their errors, based on replicate variation. A loess smooth function was applied to the mortality data for each replicate in turn, assuming binomial errors, using logit link in order to determine the contribution of smoothing to the linear fit. One way analysis of variance was used to compare $\mathrm{LC}_{50} \mathrm{~s}$ in order to determine the significance of colony (male) effects. The $\mathrm{LC}_{50} \mathrm{~s}$ from the two collections were compared by t-test and Wilcoxon rank tests, and Tukeys LSD was calculated in order to compare individual colonies. The slopes of the dose responses were compared between field collections and lab-lab crosses using t-tests.

The results of the two dose tests were analysed using a principal components analysis in which the scores (mortalities) were transformed by taking the probit of the mortalities. The next stage involved maximising the variance of transformed mortalities for the two dose groups, on orthogonal axes. The coefficients identified from this process $(0.348$ for the lower dose, and 0.938 for the higher dose) were used to weight the mortality data, for ranking the responses to the two doses. The influence of geographical location on ranked mortality was then investigated for each collection using a polynomial model.

\section{Dosage-mortality tests}

\section{RESULTS}

There was a ca. 14-fold range in the $\mathrm{LC}_{50}$ of progeny from 20 lab-field crosses to Cry IB toxin (Table 1$)$. Heterogeneity ( $\mathrm{X}^{2} / \mathrm{df}$, not shown) in most data was less than three, indicating a generally adequate fit of the logit model. The responses of the lablab crosses were intermediate in the range of responses, which were log-normally

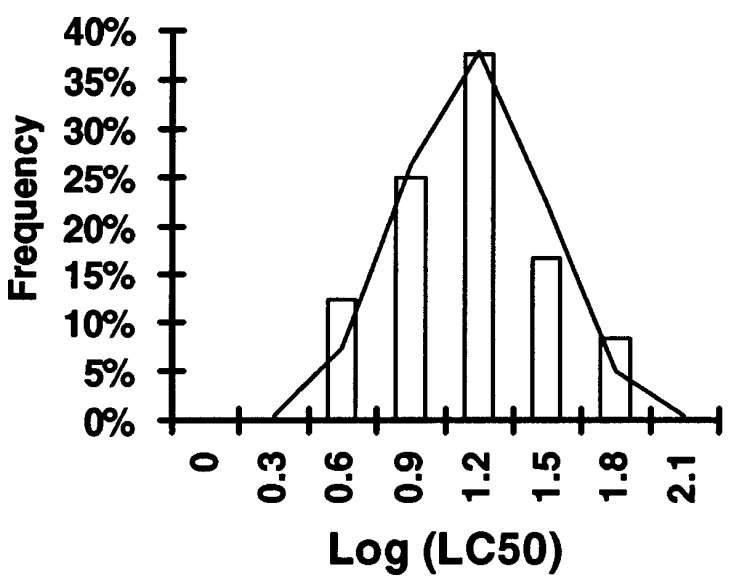

FIGURE 1: Distribution of log-transformed $\mathrm{LC}_{50}$ s to purified Cry IB toxin in artificial diet $(\mathrm{mg} / \mathrm{ml})$, for neonate Epiphyas postvittana after 14 days, compared with the expected normal distribution. 
distributed (Fig. 1). Clustering was evident in the $\mathrm{LC}_{50} \mathrm{~s}$, with significant differences present between iso-females lines $(\mathrm{P}<0.001)$. Both $\mathrm{t}$-test and Wilcoxon rank tests indicated lower $\mathrm{LC}_{50} \mathrm{~S}$ were derived from Collection 1, compared to Collection 2 $(\mathrm{t}=-3.16 ; \mathrm{df}=18 ; \mathrm{P}=0.005$ and $\mathrm{W}=30 ; \mathrm{n}=6 ; \mathrm{m}=14 ; \mathrm{P}=0.005)$.

Slopes ranged from 0.97 to 5.87 , although the majority were in the range of 1.5 to 2.5. The steep slopes were associated with high standard errors (Table 1), indicating poor agreement between replicates. The slopes were not different between the two field collections $(\mathrm{P}=0.49)$ or between either collection and the lab-lab crosses $(\mathrm{P}=0.59$ and $\mathrm{P}=0.94$, respectively).

Two Dose Tests

Principle components analysis showed that almost all of the information was in the high dose $(83 \mu \mathrm{g} / \mathrm{ml}$ diet $)$ results. Mortality values from high and low doses were weighted accordingly, and ranked. Samples from Collection 1 showed a significant trend of mortality with latitude (Fig. 2), with more susceptible lines in the north of New Zealand $(\mathrm{F}=6.91, \mathrm{df}=1 ; \mathrm{P}=0.014)$. The results from Collection 2 , which covered a narrower range of latitudes (all at or above $37^{\circ} \mathrm{S}$ ) showed a similar trend with latitude $(\mathrm{F}=3.6, \mathrm{df}=1.2, \mathrm{P}=0.06$, data not shown $)$. However, there was a significant difference in the weighted mortality results from the two collections $(\mathrm{P}=0.015)$. This indicates that progeny of samples from Collection 1 were more susceptible than those taken from the same latitudes during the second collection.

TABLE 1: Dose responses of neonate Epiphyas postvittana to purified cry IB toxin in artificial diet $(\mathrm{ug} / \mathrm{ml})$, after 14 days. Colonies resulted from individual lab-wild crosses at a range of locations in New Zealand, collected using tethered virgin females from a laboratory strain mated to feral male moths.

\begin{tabular}{lrrrrrrrr}
\hline Colony & Collection $\begin{array}{r}\text { No. of } \\
\text { insects }\end{array}$ & slope & se & LC $_{50} 1$ & $95 \%$ & CL & Ratio $^{2}$ \\
\hline 36 & 1 & 166 & 1.45 & 0.59 & 2.61 & 1.50 & 4.57 & 1.0 \\
176 & 1 & 196 & 5.01 & 3.44 & 3.10 & 1.96 & 4.89 & 1.2 \\
2 & 1 & 133 & 2.42 & 0.54 & 3.89 & 2.46 & 6.14 & 1.5 \\
228 & 2 & 205 & 1.72 & 0.20 & 5.27 & 3.34 & 8.33 & 2.0 \\
27 & 1 & 227 & 1.40 & 0.44 & 5.50 & 3.48 & 8.68 & 2.1 \\
232 & 2 & 333 & 2.42 & 0.24 & 5.53 & 3.49 & 8.72 & 2.1 \\
304 & 2 & 154 & 2.08 & 0.29 & 7.42 & 4.70 & 11.71 & 2.8 \\
lab3 & 2 & 327 & 1.94 & 0.20 & 7.48 & 4.74 & 11.81 & 2.9 \\
248 & 2 & 225 & 1.88 & 0.45 & 7.69 & 4.88 & 12.15 & 2.9 \\
163 & 1 & 115 & 1.90 & 0.58 & 9.79 & 6.20 & 15.45 & 3.8 \\
129 & 1 & 243 & 3.45 & 0.88 & 11.11 & 7.04 & 17.55 & 4.3 \\
300 & 2 & 254 & 0.97 & 0.17 & 11.38 & 7.21 & 17.96 & 4.4 \\
241 & 2 & 195 & 1.57 & 0.48 & 11.67 & 7.41 & 18.47 & 4.5 \\
249 & 2 & 186 & 1.68 & 0.01 & 11.78 & 7.45 & 18.59 & 4.5 \\
259 & 2 & 243 & 5.87 & 3.09 & 13.18 & 8.35 & 20.81 & 5.1 \\
305 & 2 & 282 & 1.81 & 0.21 & 13.68 & 8.67 & 21.59 & 5.2 \\
Lincoln & 1 & 259 & 5.87 & 4.15 & 14.71 & 9.32 & 23.22 & 5.6 \\
lab1 & 1 & 333 & 2.15 & 0.48 & 15.80 & 10.00 & 24.93 & 6.1 \\
237 & 2 & 319 & 2.15 & 0.47 & 16.37 & 10.37 & 25.84 & 6.3 \\
252 & 2 & 322 & 2.24 & 0.10 & 18.10 & 11.47 & 28.57 & 6.9 \\
lab2 & 1 & 313 & 2.31 & 0.36 & 19.53 & 12.37 & 30.82 & 7.5 \\
280 & 2 & 134 & 1.91 & 0.25 & 25.15 & 15.94 & 39.71 & 9.6 \\
318 & 2 & 242 & 2.40 & 0.42 & 33.37 & 21.13 & 52.69 & 12.8 \\
329 & 2 & 141 & 1.80 & 1.06 & 37.33 & 23.64 & 58.93 & 14.3 \\
\hline
\end{tabular}

${ }^{1} \mathrm{LC}_{50} /$ lowest $\mathrm{LC}_{50}$

${ }^{2} \mathrm{LSD}$ (Tukey) at $5 \%$ significance level is 3.47 


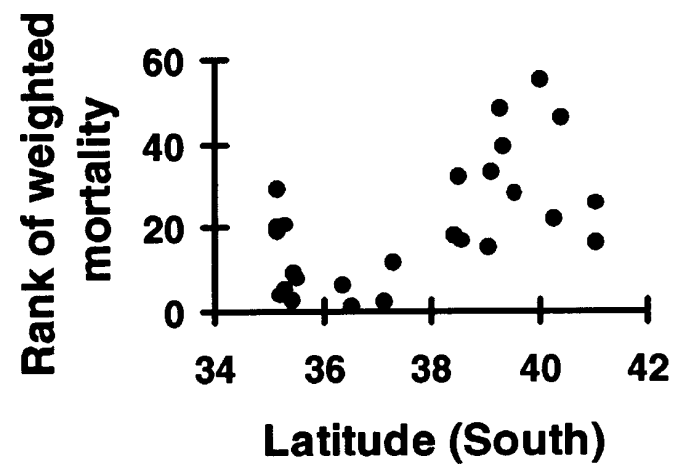

FIGURE 2: Rank of weighted mortality of neonate Epiphyas postvittana to purified Cry IB toxin, as a function of the latitude where colonies were collected in 1993.

\section{DISCUSSION}

The difference in $\mathrm{LC}_{50}$ s to Cry IB toxin between the two field collections, which were made at different sites, $\mathrm{ca}$. 12 months apart, could indicate geographic variation in dose-response in the field. Geographic variation in other traits in this species, including iso-enzymes and insecticide resistance, has been recorded previously (Suckling and Khoo 1993). Alternatively, a change in response under laboratory culture over four generations may have occurred. Changes to chemical and microbial insecticide dose responses have been recorded in laboratory colonies of insects (Robertson et al. 1995). These possible explanations were examined using the two dose tests. A comparison of weighted mortalities from the two doses, of iso-females lines collected at the same time from Northern and Central North Island sites confirmed greater susceptibility in lines collected from the northern sites. However, a comparison between lines from geographically similar Central North Island sites during the two collections also indicated a significant difference in response to Cry IB toxin. Hence it appears that both factors may have contributed to the observed differences. It is not clear whether the trend for decreased tolerance with southern latitude has any biologically important basis, although it was described by a third order polynomial $\left(\mathrm{r}^{2}=0.65\right)$.

The lack of difference in slopes between collections suggests that a similar range of genetic and/or phenotypic variability was present in each case, despite the difference in $\mathrm{LC}_{50}$ s. Chilcutt and Tabashnik (1995) recently highlighted the frequent occurrence of poor linkage between slope and $\mathrm{LC}_{50}$ in an analysis of 41 published data sets. The three bioassays of the laboratory colony indicated the reproducibility of the technique (a maximum of 2.6 fold difference in $\mathrm{LC}_{50}$ ). Our approach was to cross laboratory and feral insects to facilitate colony collection. Therefore we predominantly measured single parent (male) effects, and the true variation in the field population is likely to be close to double the measured variation.

Tabashnik (1994) summarised the reported variation in response to Bt strains (24 surveys) and endotoxins (three surveys) in a range of insects. For Lepidoptera without resistance present in the field, the range in $\mathrm{LC}_{50}$ to a purified toxin (Cry IA(c)) was up to 16 fold. The range of responses that we found was well within this range. Where resistance was present (diamondback moth resistance to CryIA(b)), this range exceeded 200 fold.

In the only other study on variation to $\mathrm{Bt}$ or a $\mathrm{Bt}$ endotoxin in a tortricid, Van Frankenhuyzen et al. (1995) reported significant genetic variation between families 
of spruce budworm, but not between widely separated field populations. Their conclusion was that the potential for resistance existed, given sufficient selection pressure.

The likelihood of evolution of field resistance to Bt toxin expressed in plants by E. postvittana is dependent on several operational factors (Georghiou and Taylor 1977). In New Zealand, selection pressure from foliar application is likely to be very limited, due to the very restricted use of formulated products, which are currently relatively ineffective on apples (Suckling et al. 1993). Their use on kiwifruit is more significant through the increasing use of $\mathrm{Bt}$ for caterpillar control (McKenna et al. 1995).

Gene flow is a major factor limiting resistance evolution (Comins 1977), but only limited information is available on gene flow in orchard tortricids in New Zealand. Suckling and Khoo (1993) used isozyme frequency to investigate population structure in E. postvittana, and reported no evident barriers to gene flow evident within the Nelson region, although one different (putative) allele was identified in a Christchurch population, four hundred kilometers away. Suckling et al. (1994) recorded the high immigration potential of this species into orchards. Caprio and Suckling (1995) demonstrated the theoretical importance of untreated refugia around the crop, in reducing the risk of resistance. The risk of resistance would therefore be most significant in areas with large areas of habitat with genetically modified plants. This point was elucidated by Wigley et al. (1994), who recognised the risk of expressing the same toxin gene in several hosts of leafrollers, such as white clover, apples, kiwifruit and Pinus radiata.

Variation exists in the dose-response of E. postvittana to Cry IB, which has now been estimated. These data represent the baseline measurement of variation for future comparison with field strains, as well as colonies which are currently under selection for resistance, as part of our programme to improve and manage the valuable resource of transgenic pest control using Bt toxins.

\section{ACKNOWLEDGEMENTS}

Funding was provided by the Foundation for Research Science and Technology for "Conserving the Benefits of Pest Resistant Transgenic Plants" (HortResearch Contract CO6513).

\section{REFERENCES}

Bradford, M.M., 1976. A rapid and sensitive method for the quantitation of microgram quantities of protein utilizing the principle of protein-dye binding. Anal. Biochem 72: $248-254$.

Caprio, M.A. and Suckling, D.M., 1995. Mating disruption reduces the risk of resistance development to transgenic apple orchards: Simulations of the lightbrown apple moth. Proc. 48th N.Z. Plant Prot. Conf.: 52-58.

Chambers, J.M. and Hastie, T.J., 1993. Statistical models. S. Wadsworth and Brooks, Pacific Grove, CA. 608p.

Chilcutt, C.F. and Tabashnik, B.E., 1995. Evolution of resistance and slope of the concentration-mortality line: are they related? J. Econ. Entomol. 88: 11-20.

Christie, R., 1993. Plant protection and international trade. Pp.1-7In: Plant Protection: Costs, Benefits and Trade Implications. D.M. Suckling and A. Popay (Eds), N.Z. Plant Protection Society, Christchurch. 161p.

Comins, H.N., 1977. The development of insecticide resistance in the presence of migration. J. Theor. Biol. 64: 177-197.

Frankenhuyzen, K. van, Nystrom, C.W. and Tabashnik, B.E., 1995. Variation in tolerance to Bacillus thuringiensis among and within populations of the spruce budworm (Lepidoptera: Tortricidae) in Ontario. J. Econ. Entomol. 88: 97-105.

Georghiou, G.P. and Taylor, C.E. 1977. Operational influences in the evolution of insecticide resistance. J. Econ. Entomol. 70: 653-658.

McGaughey, W.M. and Whalon, M.E., 1992. Managing insect resistance to Bacillus thuringiensis toxins. Science 258: 1451-1455. 
McKenna, C.E., Stevens, P.S. and Steven, D., 1995. A new Bacillus thuringiensis product for use on kiwifruit. Proc. 48th N.Z. Plant Prot. Conf.: 135-138.

Robertson, J.L., Preisler, H.K., Ng, S.S., Hickle, L.A. and Gelernter, W.D., 1995. Natural variation: A complicating factor in bioassays with chemical and microbial insecticides. J. Econ. Entomol. 88: 1-10.

Singh, P., 1983. A general purpose laboratory diet mixture for rearing insects. Insect Sci. Application 4: 357-362.

Suckling, D.M., 1996. The status of insecticide and miticide resistance in New Zealand. In: Pesticide Resistance: Prevention and Management. G.W. Bourdot and D.M. Suckling (Eds), N.Z. Plant Protection Society, Christchurch. 239 p.

Suckling, D.M., Armstrong, K.F. and Khoo, J.G.I., 1990. Selection with azinphosmethyl influences glutathione S-transferase in the lightbrown apple moth (Lepidoptera: Tortricidae). Pestic. Biochem. Physiol. 38: 9-17.

Suckling, D.M., Burnip, G.M., Brunner, J.F. and Walker, J.T.S., 1994. Dispersal of Epiphyas postvittana (Walker) and Planotortrix octo Dugdale (Lepidoptera: Tortricidae) at a Canterbury, New Zealand orchard. N.Z. J. Crop Hort. Sci. 22: 225-234.

Suckling, D.M. and Khoo, J.G.I., 1993. Decline in frequency of azinphos-methyl resistance in lightbrown apple moth (Lepidoptera: Tortricidae). J. Econ. Entomol. 86: $1308-1316$.

Suckling, D.M., Shaw, P.W. and Brown, B. 1993. Efficacy of Bt, carbaryl and pyrethrum against lightbrown apple moth. Proc. 46th N.Z. Plant Prot. Conf.: 141145.

Tabashnik, B.E., 1994. Evolution of resistance to Bacillus thuringiensis. Ann. Rev. Entomol. 39: 47-79.

Wearing, C.H. and Hokkanen, H., 1994. Pest resistance to Bacillus thuringiensis: Case studies of ecological crop assessment for Bt gene incorporation and strategies of management. Biocont. Sci. Tech. 4: 573-590.

Wearing, C.H., 1995. Resistance of Planotortrix octo to organophosphate insecticides in Dumbarton, Central Otago. Proc. 48th N.Z. Plant Prot. Conf. : 40-45.

Wigley, P.J., Chilcott, C.N. and Broadwell, A.H., 1994. Conservation of Bt efficacy in New Zealand through the planned deployment of Bt genes in transgenic crops. Biocont. Sci. Tech. 4: 527-534. 